\title{
Finite Element Analysis Of Rigid Pavement USING EVERFE2.24\& COMPARISION OF RESULTS WITH IRC58-2002 \& IRC58-2015
}

\author{
Dr. Praveen Aggarwal ${ }^{1}$ and Sheetesh Kumar Dwivedi ${ }^{2}$ \\ ${ }^{1}$ professor Civil Engineering department (Transportation wing) \\ N.I.T. Kuruksheta-136119 \\ ${ }^{2}$ M.Tech student \\ Civil Engineering department (Transportation wing) \\ N.I.T. Kuruksheta-136119
}

\begin{abstract}
In this study analysis of plain cement concrete pavement was done with 3-D mechanistic FEM computer programme EVERFE2.24. This programme was developed by Bill David, University of Maine,USA. Rigid pavement is modelled as a flat slab with DLC as base course and subgrade beneath it.

Stresses in rigid pavement at critical location was calculated due to combined effect of axle load and environmental factor.These results are compared with IRC58-2015\&2002.The disparity between results are analysed and plotted on graph.

This study finds that stressesgiven by IRC58-2015 is up to 42\% less than that given by IRC58-2002, and stresses given by EverFE2.24 is nearly same as given by IRC58-2002.italso highlighted some issues related to new code of design i.e. IRC58-2015.
\end{abstract}

\section{KEYWORDS}

FEM,EVERFE2.24,DLC,RIGIDPAVEMENT.

\section{INTRODUCTION}

During the past decade the use of three dimensional(3-D) finite element(FE) method for analysing stresses in rigid pavement have grown significantly. The finite element method enables researchers to better understand the critical behaviour of pavement which cannot be captured with conventional analytical methods such as slab- base shear transfer, load transfer efficiency of dowel and tie bar and response of pavement due to dynamic loading.

InMathematics,finite element method (FEM) is a numerical technique for finding approximate solution to boundary value problem for partial differential equation. It uses subdivision of a whole problem domain into simpler parts, called finite elements, and variationalmethods from the calculus of variation to solve the problem by minimizing an associated error function. Analogous to the idea that connecting many tiny straight lines can approximate a larger circle, FEM encompasses methods for connecting many simple element equations over many small subdomains, named finite elements, to approximate a more complex equation over a larger domain.

In this study rigid pavement is modelled as flat slab having dimension $4.5 \times 3.5 \mathrm{~m}$ which is generally taken in design.Subgrade is considered as tensionless dense liquid foundation and DLC as base course. Various material properties of component layer and loading pattern are varied to DOI:10.5121/civej.2016.3102 
observe the effect of these factors on pavement stressesThe main objectives of the study are following:

- To study the effect of modulus of sub grade reaction on pavement response using EverFE2.24.

- To study the effect of temperature differential on pavement stresses using EverFE2.24.

- To study the effect of slabthicknesson pavement stresses using EverFE2.24.

- Compare the results given by EverFE2.24 with IRC58-2002\&IRC58-2015.

- Reveal the disparity and showing it through graph.

\section{EVERFE2.24}

EverFE2.24 is 3D finite element analysis programme for JPCC pavement.Itwas developed by Bill David, University of Maine,USA.It employs several element types to discretize rigid pavement system having from one to nine slab units.In this upto three elastic base layer below the slab can be specified and subgrade can be modelled as dense liquid foundation with tension less or tension supporting.Twenty-node quadratic hexahedral elements are used to discretize the slabs and elastic base layers and the dense liquid foundation is incorporated via numericallyintegrated, 8-noded quadratic elements that are meshed with the bottom-most layer of solidelements. Linear or nonlinear aggregate interlock joint load transfer as well as dowel load transfercan be modelled at transverse joints. Load transfer across longitudinal joints via transverse tie barscan also be modelled.

\section{Detail Of The Model Used In The STUdy}

1.Slab dimension $=4.5 \times 3.5 \mathrm{~m}$

2.Slab Thicknesses $=20 \mathrm{~cm}, 25 \mathrm{~cm}$ and $30 \mathrm{~cm}$.

3.Modulus of elasticity of slab, $\mathrm{E}=30000 \mathrm{Mpa}$

4. Poisson's ratio, $\mu=0.15$, density, $\gamma=2400 \mathrm{~kg} / \mathrm{m}^{3}$

5. Coefficient of thermal expansion, $\alpha=10 \times 10^{-6} /^{0} \mathrm{C}$

6. Positive linearTemperaturedifferential with $\Delta \mathrm{t}=10^{\circ} \mathrm{C}(10-0,20-10,30-20,60-50)$ is taken.

7. Base is $100 \mathrm{~mm}$ DLC(dry lean concrete) withE $=13600 \mathrm{Mpa}, \mu=0.20 \& \gamma=2400 \mathrm{~kg} / \mathrm{m}^{3}$

8.There are three types of subgrade is taken with $\mathrm{k}$ value $42 \mathrm{MPa} / \mathrm{m}, 48 \mathrm{MPa} / \mathrm{m} \& 55 \mathrm{MPa} / \mathrm{m}$. Since the base is $100 \mathrm{~mm}$ DLC, So Effective $\mathrm{k}$ became $166 \mathrm{MPa} / \mathrm{m}, 208 \mathrm{MPa} / \mathrm{m} \quad \& 278 \mathrm{MPa} / \mathrm{m}$ respectively.

9.Loading $=100 \mathrm{KN}$ (single axle dual wheel placed critically according to IRC58-2015 as shown in screen shot of EverFE2.24,Fig1)

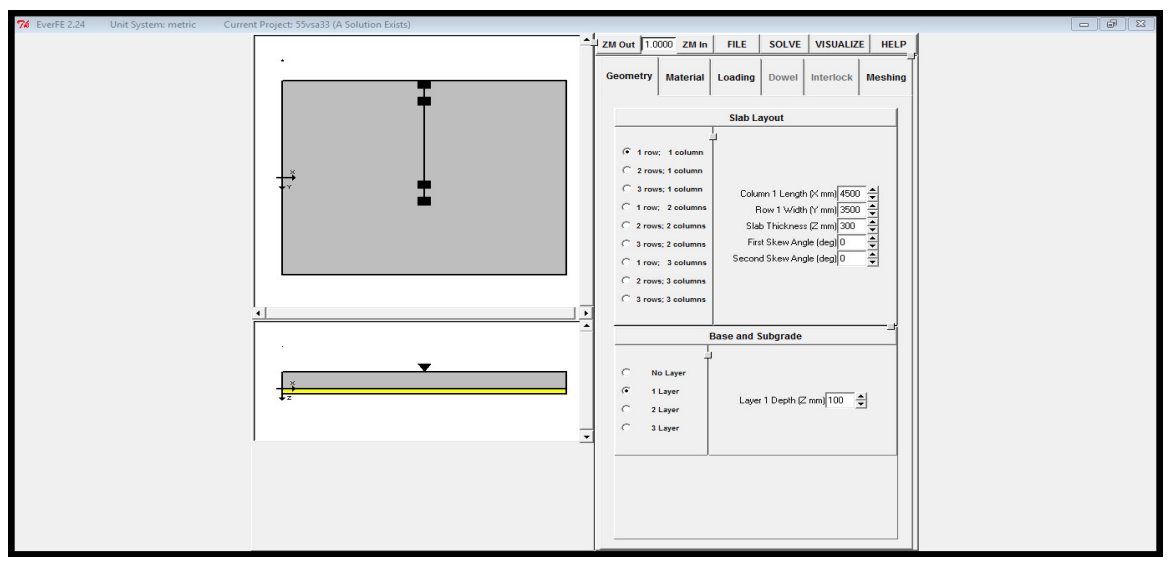

Fig1: Screen shot of EverFE2.24 to demonstrate loading pattern 
Civil Engineering and Urban Planning: An International Journal(CiVEJ) Vol.3,No.1, March 2016

\section{Details Of Results}

The details of maximum edge stresses given by EverFE2.24, IRC58-2015 and IRC58-2002 for different type of pavement and loading condition are coated in table1.

Table 1: Value of maximum edge tensile stresses in concrete pavement.

\begin{tabular}{|c|c|c|c|c|c|}
\hline \multirow[t]{2}{*}{ k-value } & \multirow{2}{*}{$\begin{array}{l}\text { Slab } \\
\text { thickness }(\mathrm{cm})\end{array}$} & \multirow{2}{*}{$\begin{array}{l}\text { Temperature } \\
\text { differential }\end{array}$} & \multicolumn{3}{|c|}{ Max tensile stresses(MPa) } \\
\hline & & & $\begin{array}{l}\text { IRC58- } \\
2002\end{array}$ & $\begin{array}{l}\text { IRC58- } \\
2015\end{array}$ & EverFE2.24 \\
\hline \multirow{12}{*}{ 42Mpa/m } & \multirow[t]{4}{*}{20} & $10-0^{0} \mathrm{C}$ & 3.4853 & 2.8186 & 3.9393 \\
\hline & & $20-10^{0} \mathrm{C}$ & 3.4853 & 2.8186 & 3.9390 \\
\hline & & $30-20^{\circ} \mathrm{C}$ & 3.4853 & 2.8186 & 3.9387 \\
\hline & & $60-50^{\circ} \mathrm{C}$ & 3.4853 & 2.8186 & 3.9379 \\
\hline & \multirow[t]{4}{*}{25} & $10-0^{0} \mathrm{C}$ & 2.8052 & 1.9839 & 2.8722 \\
\hline & & $20-10^{\circ} \mathrm{C}$ & 2.8052 & 1.9839 & 2.8719 \\
\hline & & $30-20^{\circ} \mathrm{C}$ & 2.8052 & 1.9839 & 2.8716 \\
\hline & & $60-50^{0} \mathrm{C}$ & 2.8052 & 1.9839 & 2.8708 \\
\hline & \multirow[t]{4}{*}{30} & $10-0{ }^{0} \mathrm{C}$ & 2.2709 & 1.5356 & 2.1156 \\
\hline & & $20-10^{\circ} \mathrm{C}$ & 2.2709 & 1.5356 & 2.1152 \\
\hline & & $30-20^{\circ} \mathrm{C}$ & 2.2709 & 1.5356 & 2.1169 \\
\hline & & $60-50^{\circ} \mathrm{C}$ & 2.2709 & 1.5356 & 2.1161 \\
\hline \multirow{12}{*}{ 48Mpa/m } & \multirow[t]{4}{*}{20} & $10-0^{0} \mathrm{C}$ & 3.4455 & 2.8066 & 3.9252 \\
\hline & & $20-10^{0} \mathrm{C}$ & 3.4455 & 2.8066 & 3.9249 \\
\hline & & $30-20^{\circ} \mathrm{C}$ & 3.4455 & 2.8066 & 3.9246 \\
\hline & & $60-50^{\circ} \mathrm{C}$ & 3.4455 & 2.8066 & 3.9166 \\
\hline & \multirow[t]{4}{*}{25} & $10-0^{\circ} \mathrm{C}$ & 2.8201 & 1.9707 & 2.8901 \\
\hline & & $20-10^{\circ} \mathrm{C}$ & 2.8201 & 1.9707 & 2.8898 \\
\hline & & $30-20^{\circ} \mathrm{C}$ & 2.8201 & 1.9707 & 2.8895 \\
\hline & & $60-50^{\circ} \mathrm{C}$ & 2.8201 & 1.9707 & 2.8888 \\
\hline & \multirow{4}{*}{30} & $10-0^{\circ} \mathrm{C}$ & 2.3389 & 1.5209 & 2.1458 \\
\hline & & $20-10^{\circ} \mathrm{C}$ & 2.3389 & 1.5209 & 2.1456 \\
\hline & & $30-20^{\circ} \mathrm{C}$ & 2.3389 & 1.5209 & 2.1453 \\
\hline & & $60-50^{\circ} \mathrm{C}$ & 2.3389 & 1.5209 & 2.1466 \\
\hline \multirow{12}{*}{$55 \mathrm{Mpa} / \mathrm{m}$} & \multirow[t]{4}{*}{20} & $10-0^{\circ} \mathrm{C}$ & 3.6903 & 2.7939 & 3.9086 \\
\hline & & $20-10^{\circ} \mathrm{C}$ & 3.6903 & 2.7939 & 3.9084 \\
\hline & & $30-20^{\circ} \mathrm{C}$ & 3.6903 & 2.7939 & 3.9005 \\
\hline & & $60-50^{\circ} \mathrm{C}$ & 3.6903 & 2.7939 & 3.8998 \\
\hline & \multirow[t]{4}{*}{25} & $10-0^{0} \mathrm{C}$ & 2.8189 & 1.9550 & 2.9075 \\
\hline & & $20-10^{\circ} \mathrm{C}$ & 2.8189 & 1.9550 & 2.9073 \\
\hline & & $30-20^{\circ} \mathrm{C}$ & 2.8189 & 1.9550 & 2.9070 \\
\hline & & $60-50^{0} \mathrm{C}$ & 2.8189 & 1.9550 & 2.9062 \\
\hline & \multirow[t]{4}{*}{30} & $10-0^{0} \mathrm{C}$ & 2.3831 & 1.5038 & 2.1775 \\
\hline & & $20-10^{\circ} \mathrm{C}$ & 2.3831 & 1.5038 & 2.1773 \\
\hline & & $30-20^{\circ} \mathrm{C}$ & 2.3831 & 1.5038 & 2.1770 \\
\hline & & $60-50^{0} \mathrm{C}$ & 2.3831 & 1.5038 & 2.1784 \\
\hline
\end{tabular}




\section{Presentation Of Results}

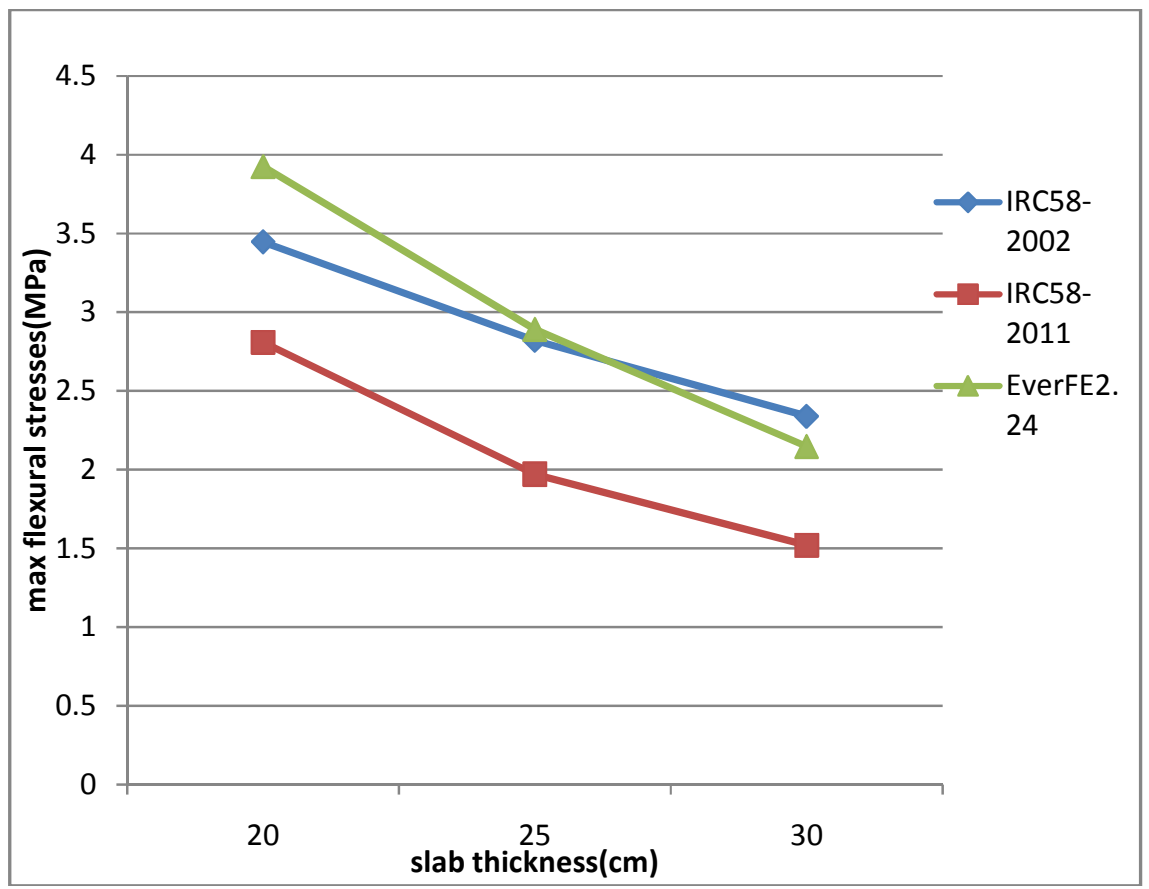

Fig2: Variation in maximum Stresses for $\Delta \mathrm{t}=10{ }^{\circ} \mathrm{C}\left(30-20{ }^{\circ} \mathrm{C}\right)$ and $100 \mathrm{Kn}$ (single axle dual wheel) in the concrete pavement for different thicknesses.

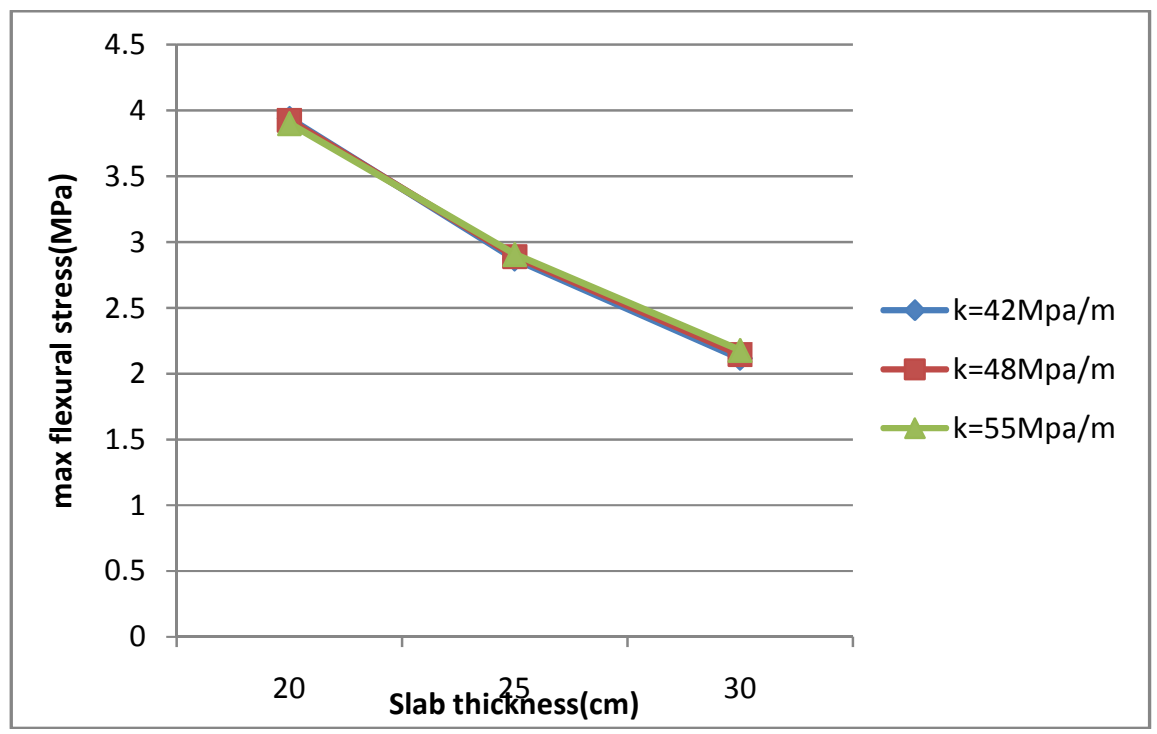

Fig3:Stresses in concrete pavement for different thicknesses given by EverFE2.24 due to $\Delta \mathrm{t}=10^{\circ} \mathrm{C}(30-20$ ${ }^{0} \mathrm{C}$ )and 100Kn (single axle dual wheel). 


\section{DiSCUSSION}

\section{The main points of discussion are mentioned below:}

1.In IRC58-2015 for stress calculation it uses effective k-value of foundation which is theoretically estimated for different combination of base as mentioned in table $3 \& 4$.if there is more than one layer is used between slab and subgrade then we cannot estimate the effective $\mathrm{k}$ value from these tables.In EverFE2.24 we use $\mathrm{k}$-value of subgrade and define material propertiessuch as E, $\mu$ etc. of other upper layer below slab for estimating the foundation strength.

2.From fig2 we can see that stresses given by regression equation mentioned in appendix- 5 of IRC58-2015 are considerably low from stresses calculated by EverFE2.24 and IRC 58-2002.This disparity is very high so cannot be considered as acceptable.

3.It is not clearly mentioned in IRC58-2015 for which dimension of slab the regression equation of appendix-5 is valid.Is these equation are valid for $4.5 \times 3.5 \mathrm{~m}$ slab as used in illustrative problem then we should adopt more acceptable equation.

4.As flexural stresses are very much affected by wheel configuration, geometry of contact area of wheel, spacing between wheels of same axle etc. but these parameter are not considered in regression equation mentioned in appendix -5 of IRC58-2015.

5.In article 5.7.5 of IRC58-2015,it is mentioned that a polythene sheet is used between DLC and slab to reduce interlayer friction to allow relative movement between slab and DLC layer but in article 6.7.1 it is mentioned that by eliminating polythene sheet, the monolithic action of two layer can be exploited to reduce the pavement thickness, which is contradictory.

6. We observe that pavement stresses are slightly affected by range of temperature differential between upper layer and lower layer of slab as given by EverFE2.24.IRC58-2015 code uses only temperaturedifferential.Although variation is very less here but for doweled and tied concrete pavement variation is more.

\section{CONCLUSION}

The flexural stresses given by IRC58-2015 is upto $42 \%$ less than that given by IRC58-2002, which is very large disparity and stresses given by EverFE2.24 is nearly same as given by IRC582002. As various otheranomalies are discussed above should be addressed so that we can make our code i.e. IRC 58-2015 more rational and acceptable.

\section{REFERENCES}

[1] IRC58-2002, GUIDELINES FOR THE DESIGN OF PLAIN JOINTED RIGID PAVEMENTS FOR HIGHWAYS (SECOND REVISION)

[2] IRC58-2015, GUIDELINES FOR THE DESIGN OF PLAIN JOINTED RIGID PAVEMENTS FOR HIGHWAYS (FOURTH REVISION)

[3] GEORGE TURKIYYAH, JOE P. MAHONEY ANDDAVID BUSH, University of Washington,Department of Civil and Environmental EngineeringBox 352700 Seattle, WA 981952700,3D FINITE ELEMENT ANALYSIS OF JOINTED PLAIN CONCRETE PAVEMENTWITH EverFE2.2

[4] SUNGHWAN KIM, HALIL CEYLAN, KASTHURIRANGAN GOPALAKRISHNAN,Department of CCEE, Iowa State University, Ames, Iowa 50011, USA , Finite element modeling of environmental effects on rigidpavement deformation.

[5] https://en.wikipedia.org/wiki/ Finite element method. 